\title{
Effect of Backrest and Torso Twist on the Apparent Mass of the Seated Body Exposed to Vertical Vibration
}

\author{
Neil J. MANSFIELD ${ }^{1 *}$ and Setsuo MAEDA ${ }^{2}$ \\ ${ }^{1}$ Department of Human Sciences, Loughborough University, Loughborough, Leicestershire, LE11 3TU, UK \\ ${ }^{2}$ Department of Human Engineering, National Institute of Industrial Health, 21-1, Nagao 6-Chome, Tama-Ku, \\ Kawasaki 214-8585, Japan
}

Received January 21, 2005 and accepted May 2, 2005

\begin{abstract}
Occupational exposure to whole-body vibration is often combined with a requirement to perform twisting actions. This paper reports a study where the effect of twisting on the biomechanical response of the seated person was investigated. Twelve male subjects were exposed to vertical random whole-body vibration at $0.4 \mathrm{~m} / \mathrm{s}^{2}$ r.m.s. Each subject sat in four different postures: 'back-on', 'backoff', 'twist' (where subjects were required to twist the torso by $9^{\circ}$ ) and 'move' (where subjects were required to performing a moving task with extended arms). Similar apparent masses were measured for the 'back-on', 'back-off' and 'twist' conditions, where a peak occurred at about $6 \mathrm{~Hz}$. For the 'move' condition, the peak in the apparent mass was attenuated indicating a different biomechanical response in this posture. The $6 \mathrm{~Hz}$ peak in fore-and-aft cross-axis apparent mass was eliminated in the 'move' condition. It is suggested that the change in biomechanical response is due to either the extended arms acting as a passive vibration absorber or that the twisting action interferes with the usual acceleration-muscle feedback system. Further work will be required to test these hypotheses.
\end{abstract}

Key words: Biomechanics, Whole-body vibration, Posture, Cross-axis transfer function

\section{Introduction}

Drivers of heavy vehicles can be exposed to whole-body vibration for extended periods of time every working day ${ }^{1}$. As occupations that involve exposure to vibration have also been associated with low back pain ${ }^{2}$, the EU is introducing legislation to enforce management of vibration risks and minimisation of exposure ${ }^{3)}$.

Although vibration is a risk factor for developing low back pain, other risks exist including prolonged sitting, lifting and poor postures ${ }^{4,5}$. Wikström $(1992)^{6}$ ) showed that subjective ratings of discomfort were greater whilst driving with twisted necks or backs than for driving in a neutral posture. Similarly, it was shown that EMG activity of the trapezius muscles increased with twist. It was concluded that allowable work times should be reduced for those

*To whom correspondence should be addressed. working with twisted postures when compared to those working in symmetrical postures.

Although there have been several laboratory studies reporting effects of posture on the biomechanical responses of the seated body, known studies have only considered postures with subjects sitting whilst facing forwards ${ }^{7-11}$. For subjects sitting in an upright posture, the effect of using a backrest on the apparent mass at the principal resonance is small. At frequencies above resonance, the apparent mass is generally slightly greater when using a backrest than when not using a backrest $\left.{ }^{7}, 9\right)$. Larger differences have been shown to occur between apparent masses measured using 'automotive' postures (semi-reclined) with a backrest when subjects are required to hold a fixed steering wheel or place hands in lap ${ }^{8)}$. When holding a steering wheel, the peak in apparent mass was reduced in both frequency and magnitude. However, when sitting upright with no backrest, very little differences were shown between apparent masses measured whilst subjects held a steering wheel or kept hands in their 
laps ${ }^{9)}$.

In work environments drivers are required to control their vehicles. This involves operation of controls (usually including large movements of a steering wheel) and repeated torso and neck movement to maintain good visibility. Many machines that expose drivers to whole-body vibration require the use of twisted postures. Twisted postures could occur whilst reversing, such as for forklift trucks, wheel loaders and dozers. Drivers of machines such as agricultural tractors, some small boats and log skidders are required to twist to monitor a towed item. Whilst performing such tasks, drivers continually change posture and perform repeated movements. Movements could be to turn steering wheels, that are often large diameter, or to change viewing aspect. There are no known published studies that have measured the apparent masses of subjects whilst performing such large movements or whilst sitting in twisted postures.

This paper reports a laboratory study which investigated the effect of backrest condition and upper body twist on apparent mass whilst exposed to vertical whole-body vibration.

\section{Methods}

Twelve male subjects participated in the experiment. Subjects had a mean age of $25.3 \mathrm{yr}$ (s.d. $4.1 \mathrm{yr}$ ), a mean stature of $171 \mathrm{~cm}$ (s.d. $6.3 \mathrm{~cm}$ ) and a mean weight of 63.8 $\mathrm{kg}$ (s.d. $9.5 \mathrm{~kg}$ ). Subjects were exposed to vertical random vibration with equal energy at each frequency from 1 to 20 Hz. The magnitude of the vibration was $0.4 \mathrm{~ms}^{-2}$ r.m.s. (unweighted) and the duration was $60 \mathrm{~s} .0 .4 \mathrm{~ms}^{-2}$ r.m.s.

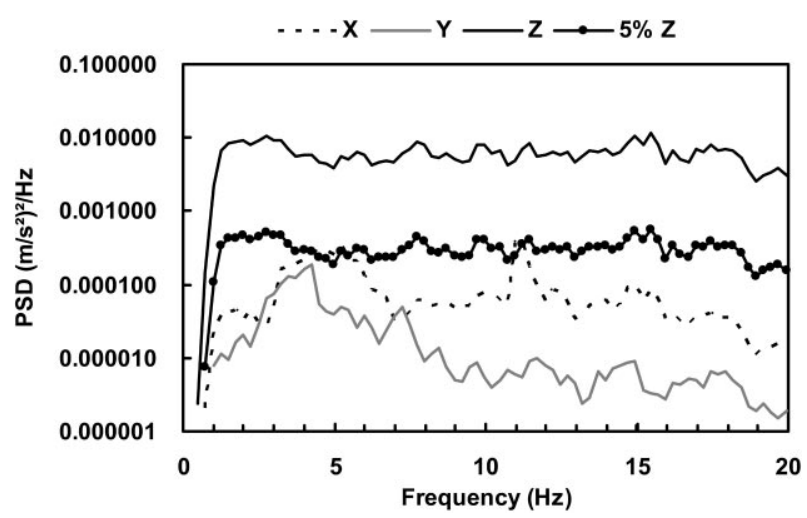

Fig. 1. Power spectral densities of measurements of vibration in the $\mathrm{x}-, \mathrm{y}$-, and $\mathrm{z}$-axes for $0.4 \mathrm{~m} / \mathrm{s}^{2}$ r.m.s. vertical vibration stimuli showing combined cross-talk from shaker and accelerometer.

Cross-axis measurements are less than $5 \%$ of the vertical data at most frequencies. was selected as the magnitude as this is typical of magnitudes experienced in many work vehicles. Vibration was generated using an IMV multi-axis shaker, driven by seven electrodynamic shakers ${ }^{12)}$ and measured using a Bruel and Kjaer 4326A triaxial accelerometer amplified using a Nexus charge amplifier. Vibration in the horizontal and rotational axes was small. Typically, measurements of vibration in the horizontal axes were less than $5 \%$ of the vertical vibration at all frequencies of interest (Fig. 1), including any contribution due to cross-axis sensitivity of the accelerometer and background noise in the measurement system. The force at the seat was measured using a Kistler $9281 \mathrm{C}$ force plate. The influence of the mass of the plate was removed using a mass cancellation technique in the frequency domain by subtracting the apparent mass of the unloaded force plate. If mass cancellation was not carried out, the modulus of the apparent masses would have been increased by a constant equivalent to the mass of the force plate. Force and acceleration signals were acquired by an HVLab data acquisition system. Data was acquired at 512 samples per second via anti-aliasing filters set at $170 \mathrm{~Hz}$.

Subjects sat on a flat horizontal seat with dimensions of 600 (w) $\times 400$ (d) $\mathrm{mm}$ which was $540 \mathrm{~mm}$ above the footrest that moved with the seat. The seat had a vertical braced backrest which was $460 \mathrm{~mm}$ wide. Subjects sat in four different postures. In the 'back-off' condition, subjects sat in a relaxed upright posture with hands lightly resting on the thighs (Fig. 2). In the 'back-on' condition, subjects sat in a relaxed upright posture with hands lightly resting on
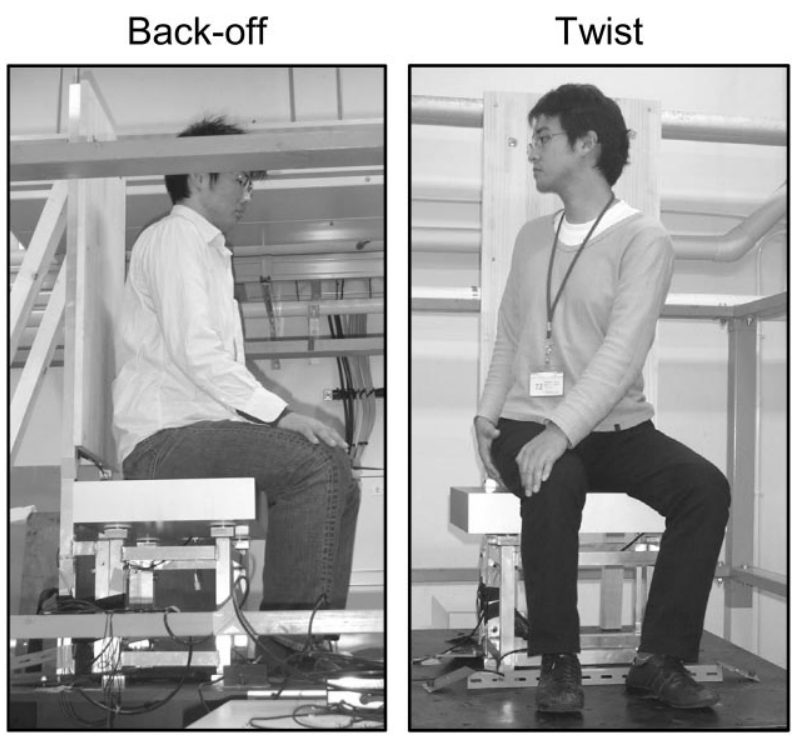

Fig. 2. 'Back-off' and 'twist' postures that were used in the experiment. 


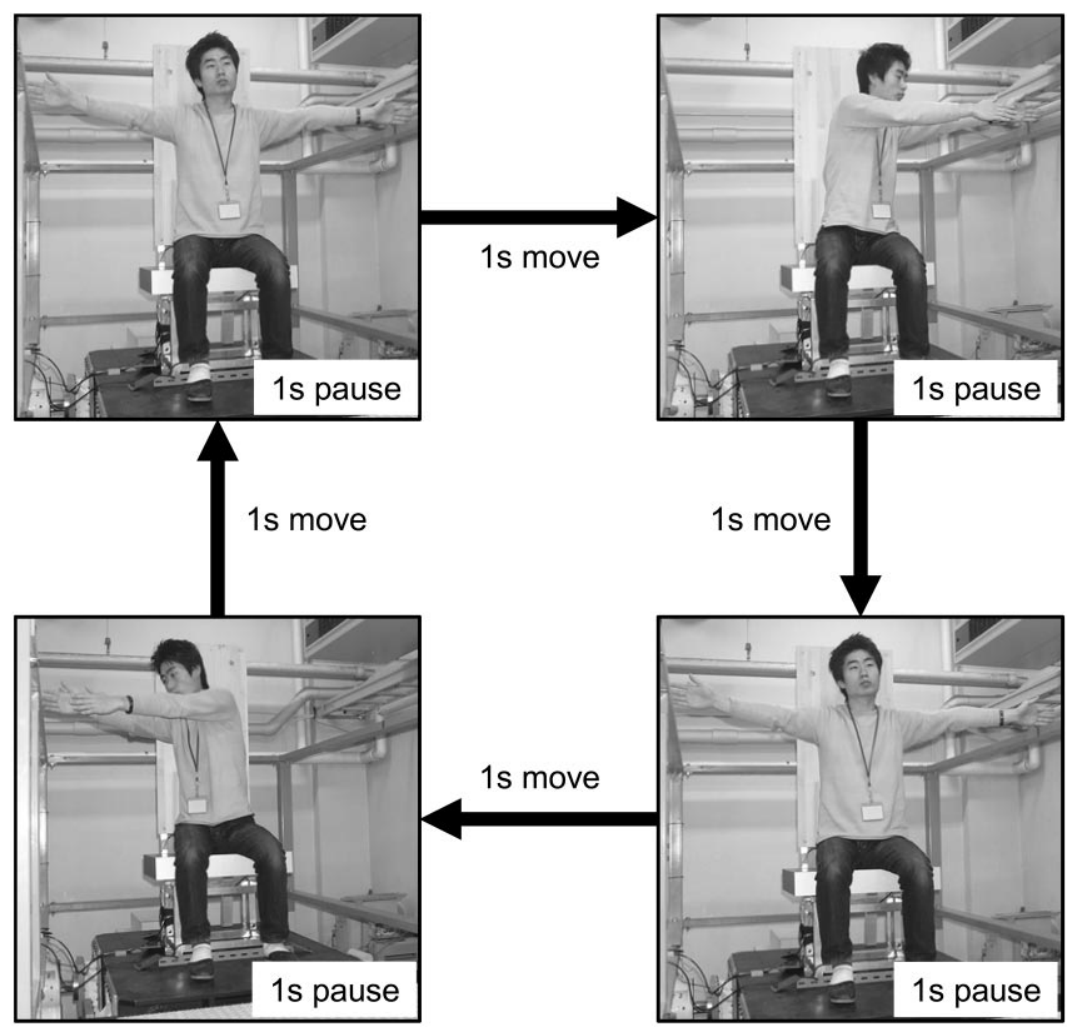

Fig. 3. Move condition used in the experiment comprising a repeated $8 \mathrm{~s}$ sequence where subjects twisted to the left and right accompanied by arm movements.

the thighs with the back in contact with the backrest. In the 'twist' condition, subjects were instructed to place hands on their right thigh and to look over their right shoulder in the coronal plane. The twist was accommodated by both the neck and lumbar spine. Shoulders were orientated at approximately $45^{\circ}$ to the mid-sagittal plane. There was no backrest contact for the 'twist' condition. The 'move' condition involved subjects repeatedly changing posture at $2 \mathrm{~s}$ intervals. In the initial position for the 'move' condition, subjects were instructed to sit in the 'back-off' position but with arms extended (Fig. 3). This posture was held for $1 \mathrm{~s}$. During the next second, the right arm was moved across the body until the fingers could touch the wrist of the left arm, the head turned to face the left and shoulders turned approximately $45^{\circ}$. This posture was held for $1 \mathrm{~s}$. During the next second, the previous movement was reversed such that subjects returned to the arms extended posture, which was held for 1s. During the next $4 \mathrm{~s}$, the movement was repeated, but to the right hand side. Thus, each cycle took $8 \mathrm{~s}$ and involved subjects turning to the left and right sequentially. The timing was controlled using an audio signal. The order of test conditions was randomised.
The experiment was approved by the Research Ethic Committee of the National Institute of Industrial Health.

Apparent masses were calculated the cross spectral density (CSD) method:

$$
H(f)=\frac{G_{i o}(f)}{G_{i i}(f)}
$$

where $G_{i o}(f)$ is the cross spectral density between the acceleration and the force, and $G_{i i}(f)$ is the power spectral density of the acceleration at frequency $f$. Transfer functions were calculated with a resolution of $0.25 \mathrm{~Hz}$. To enable apparent masses of subjects of different weights to be directly compared, the modulus of each apparent mass was normalised by dividing by the mean apparent mass modulus at $1.0 \mathrm{~Hz}$ for the 'back-on', 'back-off' and 'twist' postures (the apparent mass at $1.0 \mathrm{~Hz}$ is equivalent to the sitting weight). Coherence was calculated using:

$$
\text { coherence }(f)^{2}=\frac{/\left.G_{i o}(f)\right|^{2}}{G_{i i}(f) \times G_{o o}(f)}
$$

where $G_{o o}(f)$ is the power spectral density of the force. 


\section{Results}

Individual subject apparent masses showed peaks at about $5 \mathrm{~Hz}$ and $12 \mathrm{~Hz}$ for subjects in the 'back-on', 'back-off' and 'twist' conditions (Fig. 4). For the 'move' condition, the peak at $5 \mathrm{~Hz}$ was less apparent than in the other postures and there was no evidence of a peak at $12 \mathrm{~Hz}$ for any subject. Coherence was highest for the 'back-on', 'back-off' and 'twist' conditions. The oherence was lower for the 'move' condition, but was still above 0.9 for 11 of the 12 subjects in the range 2.5 to $20 \mathrm{~Hz}$. The drop off in the coherence at low frequencies is likely to be due to the twisting motion. Coherence for Subject 3 dropped to 0.85 at 4.5, 9.0 and $10.75 \mathrm{~Hz}$.

Normalised apparent masses for each of the 12 subjects are shown in Fig. 5. Between 1 and $2 \mathrm{~Hz}$ most subjects normalised apparent masses were lower for the 'back-on' condition than for the 'back-off' condition indicating that the backrest provided a small amount of support for the body weight. For many of the subjects, data for the 'back-on',

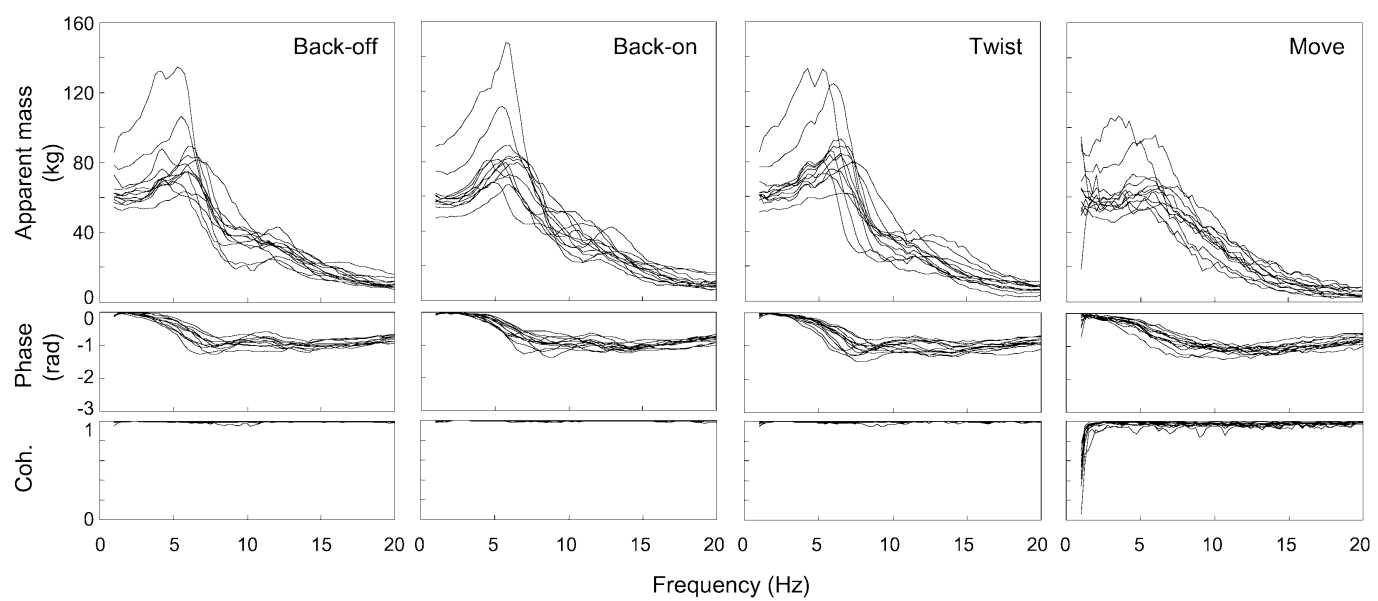

Fig. 4. Inter-subject variability in apparent mass modulus, phase and coherence for twelve subjects in four conditions exposed to random whole-body vertical vibration in the frequency range of 1 to $20 \mathrm{~Hz}$ with a magnitude of $0.4 \mathrm{~m} / \mathrm{s}^{2} \mathrm{r}$.m.s.

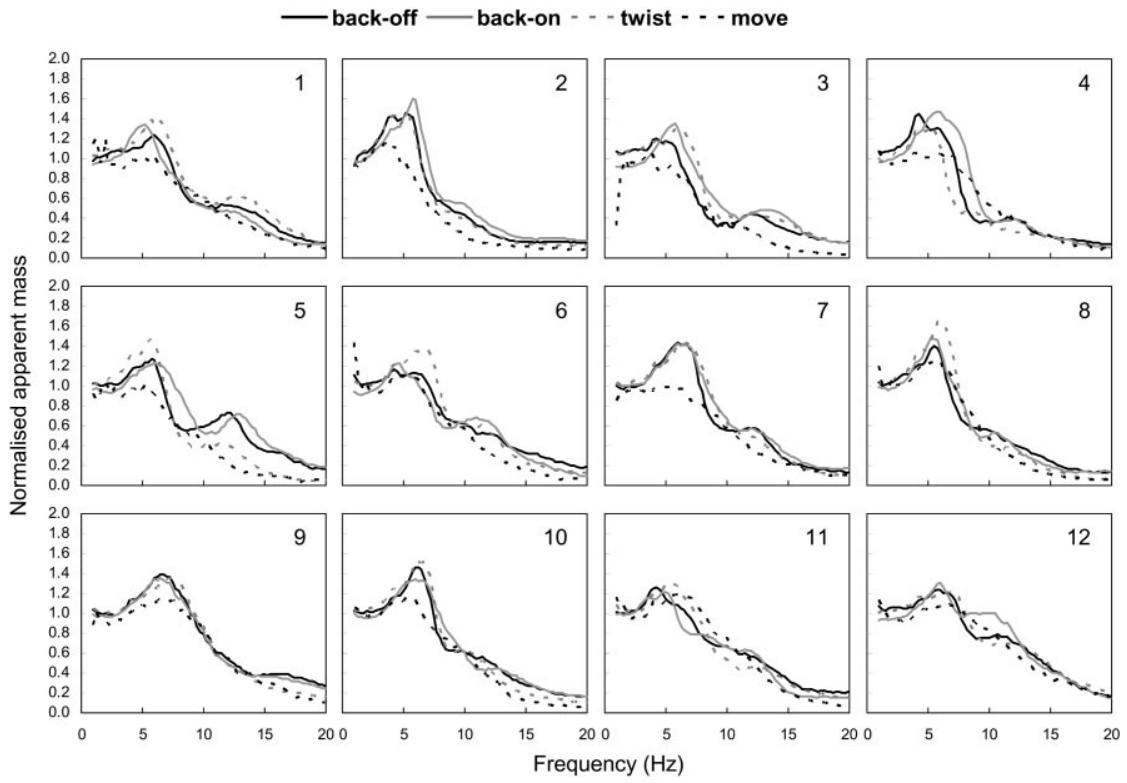

Fig. 5. Normalised apparent mass moduli for twelve subjects in four postures exposed to random whole-body vertical vibration in the frequency range of 1 to $20 \mathrm{~Hz}$ with a magnitude of $0.4 \mathrm{~m} / \mathrm{s}^{2} \mathrm{r} . \mathrm{m} . \mathrm{s}$. 
Table 1. Normalised apparent mass primary resonance frequencies and magnitudes for 12 subjects exposed to random vertical vibration at $0.4 \mathrm{~m} / \mathrm{s}^{2}$ r.m.s. and sitting in four different postures

\begin{tabular}{|c|c|c|c|c|c|c|c|c|}
\hline \multirow[b]{2}{*}{ subject } & \multicolumn{4}{|c|}{ Frequency (Hz) } & \multicolumn{4}{|c|}{ Magnitude } \\
\hline & back-off & back-on & twist & move & back-off & back-on & twist & move \\
\hline 1 & 6.00 & 5.25 & 5.75 & 5.75 & 1.23 & 1.34 & 1.38 & 1.03 \\
\hline 2 & 5.25 & 5.75 & 4.25 & 3.50 & 1.46 & 1.60 & 1.44 & 1.15 \\
\hline 3 & 4.25 & 5.75 & 6.00 & 3.75 & 1.20 & 1.35 & 1.29 & 1.07 \\
\hline 4 & 4.25 & 6.00 & 5.25 & 4.00 & 1.45 & 1.47 & 1.33 & 1.06 \\
\hline 5 & 5.75 & 6.00 & 5.75 & 5.25 & 1.27 & 1.23 & 1.47 & 1.01 \\
\hline 6 & 4.25 & 4.50 & 6.00 & 4.50 & 1.16 & 1.23 & 1.35 & 1.11 \\
\hline 7 & 6.00 & 6.00 & 6.50 & 5.50 & 1.43 & 1.42 & 1.45 & 1.00 \\
\hline 8 & 5.50 & 5.50 & 6.00 & 6.00 & 1.40 & 1.47 & 1.65 & 1.26 \\
\hline 9 & 6.50 & 6.00 & 7.50 & 6.50 & 1.39 & 1.34 & 1.35 & 1.14 \\
\hline 10 & 6.25 & 6.00 & 6.00 & 5.50 & 1.46 & 1.34 & 1.51 & 1.15 \\
\hline 11 & 4.25 & 5.00 & 5.50 & 6.00 & 1.26 & 1.21 & 1.31 & 1.19 \\
\hline 12 & 5.75 & 6.00 & 7.00 & 6.50 & 1.24 & 1.30 & 1.21 & 1.11 \\
\hline $25^{\text {th }}$ percentile & 4.25 & 5.44 & 5.69 & 4.38 & 1.24 & 1.29 & 1.33 & 1.05 \\
\hline $50^{\text {th }}$ percentile & 5.63 & 5.88 & 6.00 & 5.50 & 1.33 & 1.34 & 1.37 & 1.11 \\
\hline $75^{\text {th }}$ percentile & 6.00 & 6.00 & 6.13 & 6.00 & 1.44 & 1.43 & 1.45 & 1.15 \\
\hline
\end{tabular}

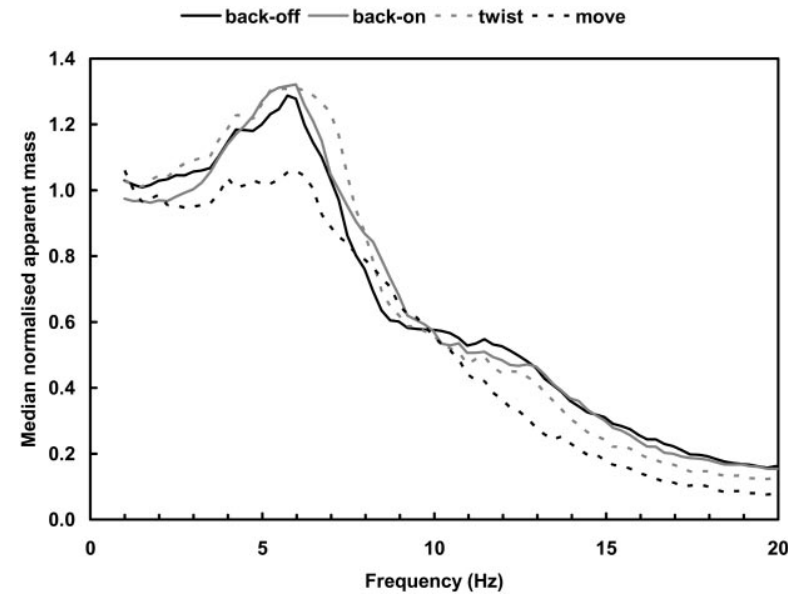

Fig. 6. Median normalised apparent masses for 12 subjects in four postures exposed to random whole-body vertical vibration in the frequency range of 1 to $20 \mathrm{~Hz}$ with a magnitude of $0.4 \mathrm{~m} / \mathrm{s}^{2}$ r.m.s.

'back-off' and 'twist' conditions were similar. For example, data for these conditions for Subjects 7 and 9 overlay one another across most of the frequency range. Other subjects (e.g. Subjects 1 and 4) show more variation between the results obtained for the first three conditions. The normalised apparent masses for the 'move' conditions were lower than for the other conditions for most subjects around resonance and at high frequencies, although this trend was not so clear for Subjects 6 and 11. The magnitude of the peak in the normalised apparent mass for the 'move' condition was lower than for all other conditions for all subjects (Table $1 ; \mathrm{p}<0.005$, Wilcoxon). There were no significant differences between the magnitudes at resonance for the 'back-off', 'back-on' or 'twist' conditions ( $p>0.05$, Wilcoxon). The median resonance frequencies were greatest for the 'twist' condition $(6.0 \mathrm{~Hz})$ and lowest for the 'move' condition $(5.5 \mathrm{~Hz})$. The differences between the resonance frequencies for the 'twist' and 'move' conditions was significant $(\mathrm{p}<0.01$, Wilcoxon), as was the difference between the 'twist' and 'back-off' conditions ( $p<0.05$, Wilcoxon). The differences between all other combinations of condition were not significant ( $>0.05$, Wilcoxon).

All subjects showed a second peak in the apparent mass for the 'back-on', 'back-off' and 'twist' conditions. For some this was a clear peak (e.g. Subjects 3 and 5) but others showed evidence of the peak by a clear change in gradient of the apparent mass (e.g. Subjects 8 and 10). No subjects showed evidence of a second peak in the apparent mass for the 'move' condition.

At frequencies below about $3 \mathrm{~Hz}$, the median normalised apparent masses had a 5\% lower modulus for the 'back-on' condition than for the 'back-off' condition and 'twist' condition (Fig. 6). Between 5 and $10 \mathrm{~Hz}$, the apparent mass modulus was greater for the 'back-on' condition than for the 'back-off' condition. The clear outlier in the median data is that for the 'move' condition where the main peak in normalised apparent mass is almost non-existent. Similarly the second peak in the median normalised apparent mass at 
about $12 \mathrm{~Hz}$ is not apparent.

\section{Discussion}

Results from this study are in general agreement with other data in the literature. The shapes of the 'back-off' and 'backon' apparent masses are similar to those previously reported. The frequencies and magnitudes of the peaks in apparent mass are similar to those in the literature, although the magnitude of vibration used in this study was lower than the magnitudes used in many previous studies. For an equivalent 'back-off' condition in two separate studies, Mansfield and Griffin ${ }^{7}{ }^{13)}$ reported median resonance frequencies of $5.27 \mathrm{~Hz}$ at $0.2 \mathrm{~m} / \mathrm{s}^{2}$ r.m.s. and $5.40 \mathrm{~Hz}$ at $0.25 \mathrm{~m} / \mathrm{s}^{2}$ r.m.s. These are comparable to the median resonance frequency of $5.63 \mathrm{~Hz}$ in this study. The median normalised magnitudes of the peaks in apparent mass in the previously reported data were 1.50 and 1.66 respectively, which are slightly higher than the value of 1.33 reported here. 'Backon' data from Mansfield and Griffin ${ }^{7)}$ measured at $0.2 \mathrm{~m} / \mathrm{s}^{2}$ r.m.s. had a peak at $5.47 \mathrm{~Hz}$ with a magnitude of 1.54 which is close to the results obtained here of $5.88 \mathrm{~Hz}$ and a magnitude of 1.34 .

Median normalised apparent masses were slightly higher for the 'back-on' condition than for the 'back-off' condition between 4 and $10 \mathrm{~Hz}$. This small effect has also been shown by Mansfield and Griffin ${ }^{7)}$ and Wang et al. ${ }^{9)}$. The differences between the normalised apparent masses with and without a backrest were significant at $8 \mathrm{~Hz}$ and $9 \mathrm{~Hz}(\mathrm{p}<0.05$, Wilcoxon), in agreement with the data of Wang et al. for non-normalised data. As part of the body weight was supported on the backrest, the origin of the 'back-on' and 'back-off' data were slightly different. This feature was retained in this study by ensuring that all data from each subject was normalised using the same constant. If normalisation was carried out on a condition-by-condition basis then the 'back-on' data would be slightly expanded and the 'back-off' data slightly compressed resulting in greater differences between the normalised apparent masses around the primary peak.

The most notable result from this study is the attenuation of the peak in the apparent mass for the 'move' condition. Coherence was slightly lower for the 'move' condition than in the other postures, although still at a level that would usually be considered acceptable. Nevertheless, the apparent mass transfer functions were recalculated using the power spectral density (PSD) method to investigate the effect of the slight incoherence between the force and acceleration signals. Whereas the CSD method only considers correlated data between the two signals, the PSD method considers all energy in the signals and can show slightly different results in the system is non-linear. The PSD method of calculating the transfer function uses the expression:

$$
H(f)=\sqrt{\frac{G_{o o}(f)}{G_{i i}(f)}}
$$

Negligible differences were found between the moduli of the apparent masses using the CSD and PSD methods for all subjects across the frequency range of interest. These data indicate that the apparent masses as reported are reliable.

An additional possibility is that the peak in the apparent mass varies depending on the stage of the cycle for the 'move' condition. To test this hypothesis, data from Subject 7, who showed the most consistent data for 'back-off', 'back-on' and 'twist', was reanalysed. Time histories of the force and acceleration were divided into $1 \mathrm{~s}$ segments and each second's apparent mass was calculated independently, using the PSD method. Although such calculations result in coarse

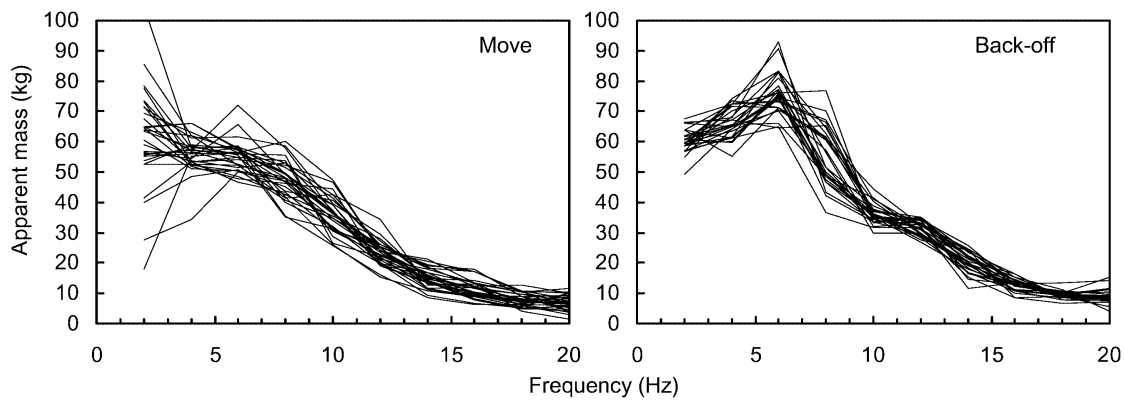

Fig. 7. Apparent masses measured for each second of vibration for Subject 7 in two different postures.

Transfer functions calculated using the PSD method and presented with a resolution of $2 \mathrm{~Hz}$. For clarity, only data from the first $30 \mathrm{~s}$ of vibration are presented. 


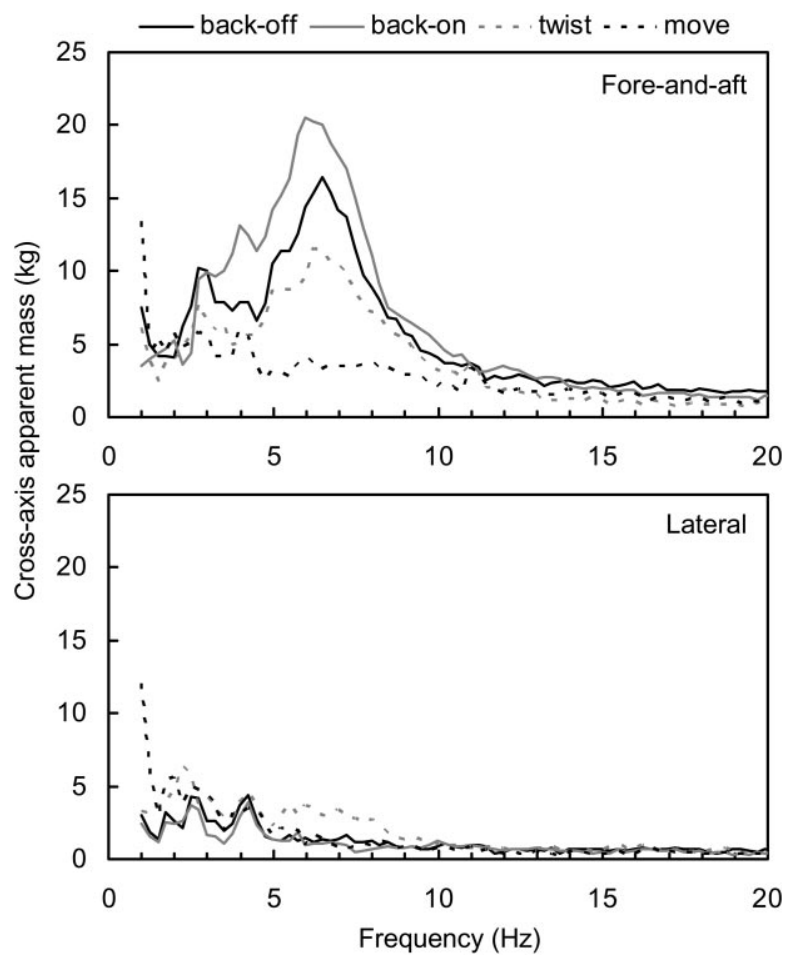

Fig. 8. Median cross-axis apparent mass of twelve subjects exposed to whole-body vertical vibration at $0.4 \mathrm{~m} / \mathrm{s}^{2}$ r.m.s. in four postures.

frequency resolutions and large variations in data, the results show that key features in the apparent mass (i.e. the frequency and magnitude of the body resonance) can be identified (Fig. 7). The shape of the apparent mass for the 'move' condition did not vary depending on the stage of the cycle, and apparent masses were similar throughout the $60 \mathrm{~s}$ measurement period.

The biomechanical response of the seated body is complex, such that single axis driving acceleration, results in forces not only in the direction of movement but also in orthogonal axes $^{10,14-16)}$. This complex response can be measured as the 'cross-axis apparent mass' which is calculated as the ratio of the force in one of the two orthogonal axes to the acceleration in the axis of motion. Nawayseh and Griffin ${ }^{10,14)}$ have shown that the cross-axis apparent masses in the foreand-aft direction have a peak at about $6 \mathrm{~Hz}$ at $0.25 \mathrm{~m} / \mathrm{s}^{2}$ r.m.s. (no backrest), but there is very little response in the lateral direction. For the 'back-off', 'back-on' and 'twist' conditions in this study, similar results were obtained to those in the literature (Fig. 8). However, the peak at $6 \mathrm{~Hz}$ was removed from the fore-and-aft cross-axis apparent mass for the 'move' condition. These data also show that the magnitude of the fore-and-aft cross-axis apparent mass depends on the posture. The fore-and-aft cross-axis apparent masses at $6 \mathrm{~Hz}$ were significantly different for all combinations of postures ( $\mathrm{p}<0.005$, Wilcoxon) with the exception of the comparison of the 'twist' and 'back-off' postures, where the difference was not significant.

The reduction in the peak of the apparent mass for the 'move' condition could be due to either the difference in posture (i.e. arms extended rather than arms on the thighs) or due to the movement itself.

Whilst sitting with arms outstretched but reaching forwards, Paddan and Griffin ${ }^{17)}$ showed peaks in the vertical transmissibility to the hand at $2 \mathrm{~Hz}$ and at 5 to $6 \mathrm{~Hz}$. This second peak coincides with the peak in the apparent mass. It is thus possible that the outstretched arms act as a passive dynamic vibration absorber ${ }^{18)}$, such that inertial forces from the hand-arm system act out of phase with the vertical forces in the torso, causing a reduced resultant force. Rakheja et $a l .^{8)}$ showed that extending arms forwards and holding a steering wheel had the effect of attenuating the peak in the apparent mass for subjects in an 'automotive' posture, although, when sitting upright, the differences were reduced ${ }^{9}$. There are no known studies that have investigated the biomechanical response of the seated person with extended arms. A relatively simple experiment could be envisaged that could confirm whether extended arms act as a passive vibration absorber whilst extended laterally and forwards.

Several studies have been reported that show EMGs of back muscles whilst exposed to vibration ${ }^{19-21)}$. These consistently show a muscular response that is correlated to the driving acceleration. Peaks in EMG occur at frequencies that are similar to those seen in the apparent mass ${ }^{20)}$. It is possible that the muscular activity required to twist the upper body interferes with the activity that would otherwise exist for passive postures, and this interference could result in a different dynamic response of the body. Future work could investigate this hypothesis by using EMG or other physiological techniques.

It is well established that working in twisted postures poses a health hazard. Although this study only showed small differences between the apparent masses measured in the 'back-on', 'back-off' and 'twist' postures, this should not be interpreted as indicating that they hold equal risk, as apparent mass is not a direct indicator of risk.

\section{Conclusions}

Apparent masses of twelve male subjects exposed to random vertical vibration were similar to those in the literature. Only small differences occurred between the apparent masses measured using the 'back-off', 'back-on', and 'twist' postures. The peak in the apparent mass was 
reduced or eliminated for subjects in the 'move' condition where subjects were required to repeatedly twist with arms extended. Similarly, the second peak in apparent mass was eliminated in the 'move' condition. Cross-axis apparent masses showed significant differences between results in each of the postures in the fore-and-aft direction. No $6 \mathrm{~Hz}$ peak was evident for the fore-and-aft cross-axis apparent mass. It is hypothesised that the reduction in the peak in the apparent mass for the 'move' condition was due to either the extended arms acting as a vibration absorber, or the twisting motion interfering with the muscular response to vibration. Further investigation is required to test these hypotheses.

\section{References}

1) Kittusamy NK, Buchholz B (2004) Whole-body vibration and postural stress among operators of construction equipment: A literature review. J Saf Res 35, 255-61.

2) Griffin MJ (1990) Handbook of human vibration. Academic, London.

3) European Commission (2002) Directive 2002/44/EC of the European Parliament and of the Council of 25 June 2002 on the minimum health and safety requirements regarding the exposure of workers to the risks arising from physical agents (vibration) (sixteenth individual Directive within the meaning of Article 16(1) of Directive 89/391/EEC). Official Journal of the European Communities L177, 13-9.

4) Magnusson ML, Pope MH (1998) A review of the biomechanics and epidemiology of working postures (it isn't always vibration which is to blame!). J Sound Vib 215, 643-52.

5) Mansfield NJ (2004) Human Response to Vibration. CRC Press, Boca Raton, Florida, USA.

6) Wikstrom BO (1993) Effects from twisted postures and whole-body vibration during driving. Int J Ind Erg 12, 61-75.

7) Mansfield NJ, Griffin MJ (2002) Effects of posture and vibration magnitude on apparent mass and pelvis rotation during exposure to whole-body vertical vibration. J Sound Vibrat 253, 93-107.

8) Rakheja S, Haru I, Boileau PE (2002) Seated occupant apparent mass characteristics under automotive postures and vertical vibration. J Sound Vib 253, 57-75.
9) Wang W, Rakheja S, Boileau P (2004) Effects of sitting postures on biodynamic response of seated occupants under vertical vibration. Int J Ind Ergonomics 34, 289306.

10) Nawayseh N, Griffin MJ (2003) Non-linear dual-axis biodynamic response to vertical whole-body vibration. J Sound Vib 268, 503-23.

11) Fairley TE, Griffin MJ (1989) The apparent mass of the seated human body: vertical vibration. J Biomech 22, 81-94.

12) Maeda $S$ (2003) Six degree of freedom electro vibrator for human response to vibration experiment. In: the 38th United Kingdom Conference on Human Response to Vibration, Gosport, England.

13) Mansfield NJ, Griffin MJ (2000) Non-linearities in apparent mass and transmissibility during exposure to whole-body vertical vibration. J Biomech 33, 933-41.

14) Nawayseh N, Griffin MJ (2004) Tri-axial forces at the seat and backrest during whole-body vertical vibration. J Sound Vib 277 (1, 2) 309-26.

15) Paddan GS, Griffin MJ (1998) A review of the transmission of translational seat vibration to the head. J Sound Vib 215, 863-82.

16) Paddan GS, Griffin MJ (1988) The transmission of translational seat vibration to the head-I. Vertical seat vibration. J Biomech 21, 191-8.

17) Paddan GS, Griffin MJ (1995) Interruption in hand control during exposure to whole-body vertical vibration. In: Contemporary Ergonomics 1995, ed. by Robertson SA, Taylor and Francis, London.

18) Irwin JD, Graf ER (1979) Industrial noise and vibration control. Prentice Hall, London.

19) Zimmermann CL, Cook TM (1997) Effects of vibration frequency and postural changes on human responses to seated whole-body vibration exposure. Int Arch Occup Environ Health 69, 165-79.

20) Bluthner R, Seidel H, Hinz B (2002) Myoelectric response of back muscles to vertical random wholebody vibration with different magnitudes at different postures. J Sound Vib 253, 37-56.

21) Robertson CD, Griffin MJ (1989) Laboratory studies of the electromograhpic response to whole-body vibration. ISVR Technical Report 184. Institute of Sound and Vibration Research, University of Southampton, Southampton. 